\title{
QFT based Robust Load Frequency Controller Design for Multi-Area Power System
}

\author{
P. Bharat Kumar ${ }^{1}$, P. Sujatha ${ }^{2}$ \\ Research Scholar, EEE Department, JNTUA CEA, Ananthapuramu, India ${ }^{1}$ \\ Professor, EEE Department, JNTUA CEA, Ananthapuramu, India ${ }^{2}$
}

\begin{abstract}
In this paper a new robust load frequency controller for two area interconnected power system is presented to quench the deviations in frequency and tie line power due to different load disturbances. The Genetic algorithm (GA) controller designed here consists of two crisp inputs namely deviation of frequency and the other is derivative of frequency deviation. The Genetic algorithm controller output is the control input to each area. In practical systems, the conventional PI type controllers are applied for Load Frequency Control. In order to improve the performance of the LFC system, Genetic Algorithm (GA) approach is used to optimize the conventional controller gains and bias factors and a robust decentralized controller using Quantitative Feedback Theory (QFT) is proposed to solve the Load Frequency Control (LFC) problem in a restructured power system that operates under deregulation based on bilateral policy scheme. In each control area of this dynamical model, the effects of the possible contracts are treated as a set of new input signals. To validate the effectiveness of all the methods, the simulation has been performed using different controllers and compared. The simulation results substantiate the robustness and high performance of QFT controller.
\end{abstract}

Index Terms: Restructured Power System, Load Frequency Control, Genetic Algorithm, Quantitative Feedback Theory, Bilateral Contracts.

\section{INTRODUCTION}

In recent years, power system restructuring has been a worldwide trend with the introduction of competitive market system under deregulation. Also, major changes have been introduced into the structure of electric power utilities all around the world. The reason for this was to improve the efficiency in the operation of power system by means of deregulating the industry and opening it up to private competition. In this frame work, consumers will have an opportunity to make a choice among various providers of electric energy. The net effect of such changes will mean that the transmission generation and distribution systems must now adapt to set of rules dictated by open markets. In power system, any sudden load perturbations cause the deviation of tie- line exchanges and the frequency fluctuations. So, load frequency control (LFC) or automatic generation control (AGC) is a very important issue in power system operation and control for supplying sufficient and reliable electric power with good quality. The main goal of AGC of a power system within specified tolerance is to maintain the frequency of each area and tie- line power flow by adjusting the MW outputs of AGC generators so as to accommodate fluctuating load demands [1]. Automatic generation control (AGC) in a multi-area interconnected power system has four principal objectives when operating in either the so-called normal or preventive operating states:

- Maintain constant generation and total system load

- To maintain system electrical frequency error to zero

- Generation of Distribution systems for control areas so that net area tie flows match net area tie flow schedules

- Distributing area generation amongst area generation sources so that area operating costs are minimized, subject to appropriate constraints of security and environmental. [2].

Power system loads and losses are sensitive to frequency. Data obtained right after frequency disturbances show that, if the frequency changes then their aggregate frequency changes. Once a generating unit is tripped or a block of load is added to the system, the power mismatch is initially compensated by an extraction of kinetic energy from system inertial storage which causes a declining system frequency. As frequency decreases, the power taken by load decreases. Equilibrium for large systems is often obtained when the frequency sensitive reduction of loads balances the output power of the tripped unit or that delivered to the added block of load at the resulting (new) frequency. If this effect halts the frequency decline it usually does so in less than 1.5 to 2 seconds. If the mismatch is large enough to cause the frequency to deviate beyond the governor dead band of generating units, governor action will be used to increase their response. For such mismatches, equilibrium is obtained when the reduction in the power taken by loads plus the increased generation due to governor action compensates for the mismatch. Such equilibrium is normally obtained within a dozen seconds after the tripping of a unit or connection of the additional load. 


\section{UGC Approved Journal}

IJIREEICE

\section{International Journal of Innovative Research in Electrical, Electronics, Instrumentation and Control Engineering \\ ISO 3297:2007 Certified \\ Vol. 5, Issue 6, June 2017}

\section{TWO AREA DEREGULATED POWER SYSTEM FOR LFC}

In the competitive environment of power system, the vertically integrated utility (VIU) no longer exists. Deregulated system will consist of GENCOs, DISCOs, and transmission companies (TRANSCOs) and independent system operator (ISO). However, the common AGC goals, i.e. restoring the frequency and the net interchanges to their desired values for each control area, still remain. The power system is assumed to contain two areas and each area includes two GENCOs and also two DISCOs as shown in Fig.1. A DISCO can contract individually with any GENCO for power and these transactions are made under the supervision of ISO.

To make the visualization of contracts easier, the concept of a "DISCO participation matrix" (DPM) will be used [2]. DPM is a matrix with the number of rows equal to the number of GENCOs and number of columns equal to number of DISCOs in the system. For the purpose of explanation, consider a two-area system in which each area has two GENCOs and two DISCOs in it. Let GENCO1, GENCO 2, DISCO 1 and DISCO 2 are in area-1, and GENCO 3, GENCO 4, DISCO 3 and DISCO 4 are in area-2 as shown in fig. 1.

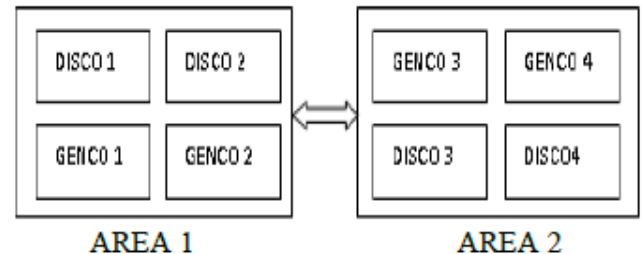

The DPM of fig 1 is:

Fig. 1: Two area power system

Table.1. DPMs

\begin{tabular}{|l|c|c|c|c|}
\hline & DISCO1 & DISCO2 & DISCO3 & DISCO4 \\
\hline GENCO1 & Cpf11 & Cpf12 & Cpf13 & Cpf14 \\
\hline GENCO2 & Cpf21 & Cpf22 & Cpf23 & Cpf24 \\
\hline GENCO3 & Cpf31 & Cpf32 & Cpf33 & Cpf34 \\
\hline GENCO4 & Cpf41 & Cpf42 & Cpf43 & Cpf44 \\
\hline
\end{tabular}

It can be thought of as a fraction of a total load contracted by a DISCO (column) toward a GENCO (row). Thus, the ijth entry corresponds to the fraction of the total load power contracted by DISCO $\mathrm{j}$ from GENCO $\mathrm{i}$. The sum of all the entries in a column in this matrix is unity. DPM shows the participation of a DISCO in a contract with a GENCO, and hence the "DISCO participation matrix". Any entry of this matrix which is named cpf (contract participation factor), corresponds to a fraction of total load power contracted by a DISCO toward a GENCO and carry information as to which GENCO has to follow a load demand by which DISCO. As a result, the sum of all the entries in a column in this matrix is unity, i.e. $\sum_{i} c p f_{i j}=1$.

Whenever a load demanded by a DISCO changes, it is reflected as a local load in the area to which this DISCO belongs. This corresponds to the local loads $\Delta P_{L 1}$ and $\Delta P_{L 2}$. As there are many GENCOs in each area, ACE signals have to be distributed among them in proportion to their participation factor in LFC which is named as apf(ACE Participation Factor).Note that $\sum_{j=1}^{m} a p f_{i j}=1$ where $\mathrm{m}$ is the number of GENCOs. The actual and scheduled steady state power flow on the tie line are given as

$$
\begin{aligned}
\Delta P_{\text {tie } 1-2, \text { scheduled }} & =\sum_{i=1}^{2} \sum_{j=3}^{4} c p f_{i j} \Delta P_{L j}-\sum_{i=3}^{4} \sum_{j=1}^{2} c p f_{i j} \Delta P_{L j} \\
\Delta P_{\text {tie } 1-2, a c t} & =\left(2 \pi \cdot T_{12} / s\right) \cdot\left(\Delta f_{1}-\Delta f_{2}\right)
\end{aligned}
$$

At any given time, the tie-line power error is defined as

$$
\Delta P_{\text {tie } 1-2, \text { error }}=\Delta P_{\text {tie 1-2,act }}-\Delta P_{\text {tie } 1-2, \text { scheduled }}
$$

Using this error signal, the respective ACE signals like as the traditional scenario are

$$
A C E_{1}=B_{1} \Delta f_{1}+\Delta P_{\text {tie } 1-2, \text { error }}
$$

$$
A C E_{2}=B_{2} \Delta f_{2}+\Delta P_{\text {tie } 2-1, \text { error }}
$$




\section{International Journal of Innovative Research in Electrical, Electronics, Instrumentation and Control Engineering \\ ISO 3297:2007 Certified}

Vol. 5, Issue 6, June 2017

The state space model of the closed loop system is characterized as

$$
\begin{gathered}
\dot{x}=A x+B u \\
\mathrm{y}=\mathrm{Cx}
\end{gathered}
$$

Where $\mathrm{x}$ is the state vector and $\mathrm{u}$ is the vector of power demands by DISCOs.

$$
\begin{aligned}
& \mathrm{u}=\left[\Delta P_{L 1} \Delta P_{L 2} \Delta P_{L 3} \Delta P_{L 4}\right]
\end{aligned}
$$

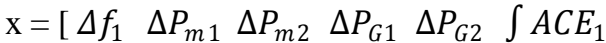

$$
\begin{aligned}
& \left.\Delta P_{\text {tie } 1-2, a c t} \Delta f_{2} \Delta P_{m 3} \Delta P_{m 4} \Delta P_{G 3} \Delta P_{G 4} \int A C E_{2}\right]
\end{aligned}
$$

\section{CONVENTIONAL PI CONTROLLER}

In conventional PI controller, the proportional controller produces a control signal proportional to error signal and integral controller reduces the steady state error. The controller transfer function obtained from conventional PI controller is

$$
G_{c}(s)=\frac{s+3}{s}
$$

The main drawback of conventional PI controller is it requires exact mathematical modeling for a given plant and it is not applicable for nonlinear systems.

\section{GENETIC ALGORITHM CONTROLLER}

The evolution of species and individual selection based on Darwin's "survival of the fittest" principle are the origin of parameter iterative search techniques known as genetic algorithm (GA). Potential solutions to the problem at hand are viewed as individuals in a population striving for survival. The degree to which solutions meet some predefined performance requirements is evaluated and used to select "surviving" individuals that will "reproduce" and generate a new population. The selection scheme is biased towards high performance solutions. A sequence of transformations inspired from genetic mutation and crossover will alter some of the individuals thus introducing new solutions into the search scheme. The cycle is repeated and provided the algorithm structure and parameters are correctly set up, there is a good probability that after a reasonable number of iterations a global optimal solution is obtained. To achieve this goal a proper balance between two contradictory elements is necessary, exploitation of the already acquired information about per formant solutions and exploration of the entire solution space.

Although a strong theoretical background is still to be built up, experimental results were very encouraging. Optimization became a major field of GA's applicability. As compared to the widely used gradient methods and enumerative schemes GA's are global and robust over a broad spectrum of problems.

The use of genetic algorithms as powerful tools for solving aerospace-related control system optimization problems. Although more efforts were found to be necessary, GA's show the potential of promising techniques, especially for solving highly complex nonlinear problems. A classical design pattern is considered with requirements expressed both in frequency and time domain. A standard GA using binary genetic representation (BR) has been successfully implemented to solve this problem. The same general algorithm set up is assumed in this paper but floating point (FP) representation and appropriate genetic operators are defined and used. Effects of elitist strategy and selective weights in the evaluation function are analyzed. Performance of the controlled system is compared with results obtained using a classical design procedure and with results obtained with the standard GA. GAs shows the potential of promising, alternative techniques for solving aerospace control system design problems. The main stages of GA are:

1. Reproduction: Selects the fittest individuals in the current population to be used in generating the next population.

2. Cross over: Causes pairs, or larger groups of individuals to exchange genetic information with one another.

3. Mutation: Causes individual genetic representations to be changed according to some probabilistic rule.

Genetic algorithms are more likely to converge to global optimal than conventional optimization techniques, since they search from a population of points, and are based on probabilistic transition rules. Conventional optimization techniques are ordinarily based on deterministic hill - climbing methods, which, by definition, will only find local optima. Genetic algorithms can also tolerate discontinuities and noisy function evaluations. In this study, the optimal values of the parameters $\Delta f_{1}$ (or) $\Delta f_{2}$ and $\Delta \dot{f}_{1}$ (or) $\Delta \dot{f}_{2}$ which minimize an array of different performance indices are easily and accurately computed using a genetic algorithm. Each individual in the initial population has an associated performance index value. Using the performance index information, the GA then produces a new population. The application of a genetic algorithm involves repetitively performing two steps.

1. The system must be simulated to obtain the value of the performance index for each individual.

2. for the next generation of individuals GA use the reproduction, cross over and mutation operators. 


\section{International Journal of Innovative Research in Electrical, Electronics, Instrumentation and Control Engineering \\ ISO 3297:2007 Certified}

Vol. 5, Issue 6, June 2017

These two steps are repeated from generation to generation until the population has converged, producing the optimum parameters. A flow chart of the genetic algorithm optimization procedure is given in fig.2. The controller transfer function obtained is

$$
\mathrm{G}_{\mathrm{c}}(\mathrm{s})=\frac{0.224 \mathrm{~s}^{2}+0.7424 \mathrm{~s}+2.1922}{\mathrm{~s}}
$$

\section{QFT CONTROLLER}

The QFT approach to robust control was proposed by Horowitz et al [15]. In QFT, the closed loop transfer function needs to assure certain performances for a set of discrete frequencies. These necessities are specified in terms of forbearance bands within which the magnitude response of the closed-loop transfer function should stretch out.

The uncertainties in the plant are transformed onto the Nichols chart consequential in bounds on the loop transmission function of a randomly chosen nominal plant. A compensator is chosen by manually shaping the loop transmission such that it satisfies the bounds at each of the frequency points. (See Fig. 3 [16]).

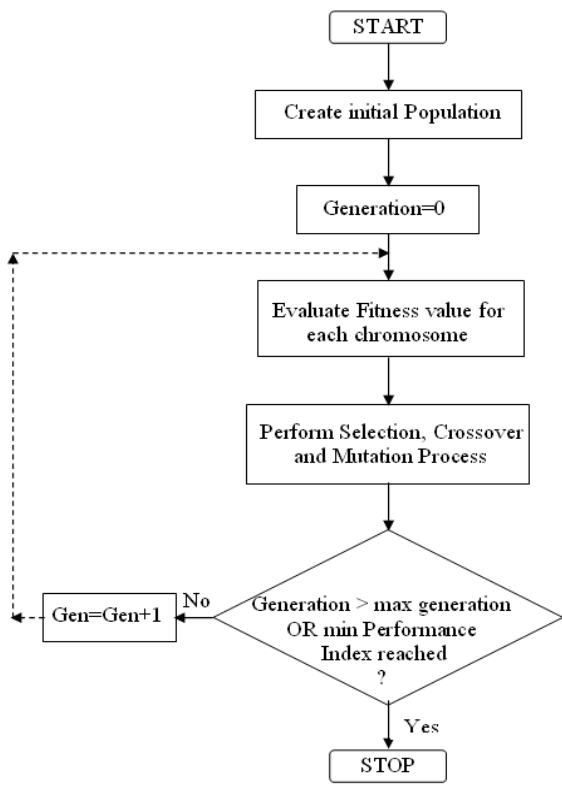

Fig.2.Genetic Algorithm flow chart

The structure of closed loop system with controllers is shown in Fig.4 Plants I and II are the transfer function matrix with uncertainty parameters and can be obtained by state space equation (6) and (7) for any operating summit. The objective is the design of G1 and G2 so that the deviation of $\Delta \mathrm{f}_{1}$ and $\Delta \mathrm{f}_{2}$ to the uncertainties in the plant are within desired values. The first tread in QFT is plotting of plant uncertainties in Nicholas chart. The word template is used to denote the set of the uncertain plant's frequency responses at a given frequency. The frequency range must be selected based on the performance bandwidth and nature of the templates. The templates of the plant of area I are obtained by simulation using Matlab QFT toolbox and are illustrated in Fig.5.

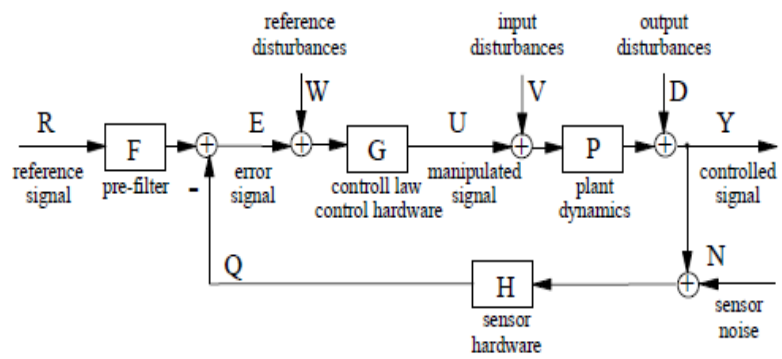

Fig.3. Single-loop feedback system

It can be seen that the template's at about frequency $\omega=200 \mathrm{rad} / \mathrm{sec}$ becomes fix. Next the tracking and disturbance rejection bounds are obtained.The goal of LFC is restoring frequency and tie power deviations to zero in the case of the 
UGC Approved Journal

IJIREEICE

\section{International Journal of Innovative Research in Electrical, Electronics, Instrumentation and Control Engineering \\ ISO 3297:2007 Certified}

Vol. 5, Issue 6, June 2017

changes in demand of areas which are known as disturbances in this problem since the problem is a regulatory one, controllers designed should only have disturbance rejection property and tracking property is redundant. So control objective of stability with reasonable margins is

$$
\left|\frac{P G(j \omega)}{1+P G(j \omega)}\right| \leq 1.2, \quad \omega>0
$$

Performance specifications are typically defined within a finite frequency bandwidth which is related to the closed loop system bandwidth and band of the disturbances. In QFT design, performance is specified only up to a finite frequency whose value is always problem reliant [18].

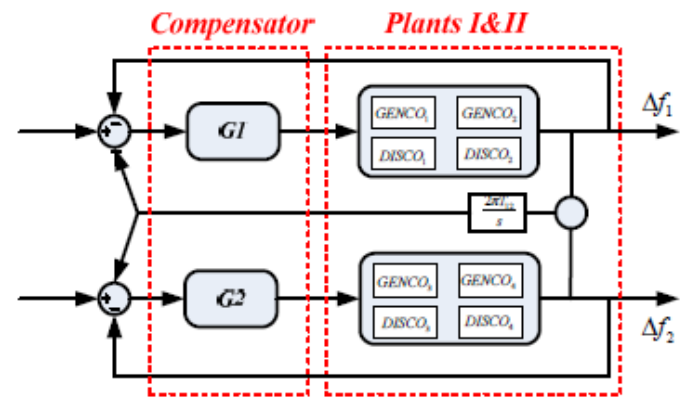

Fig.4. Structure of closed loop system for load frequency control

After evaluating stability and performance bounds, the next step in a QFT is loop shaping that involves the design of a nominal loop function that meets its bounds. Nominal loop is the product of the nominal plant and the controller that is supposed to be designed. The nominal loop has to satisfy all the bounds in the worst case also [19]. By invoking

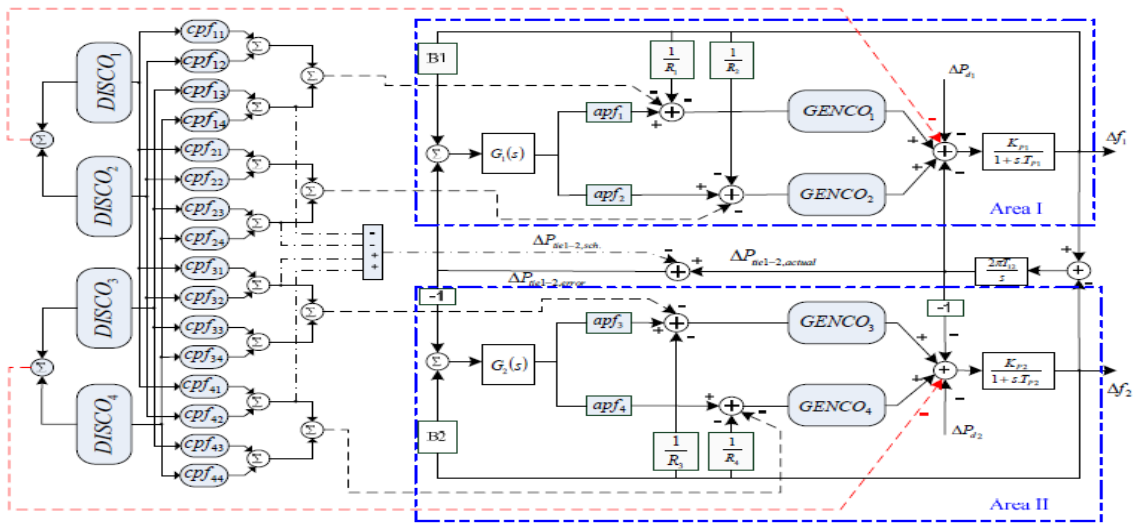

Fig.5. Modified LFC scheme for restructured power system

suitable instructions in Matlab, the result of loop shaping for this problem is the following compensator

$$
\mathrm{G}_{1}=\frac{\left(20.5432 \mathrm{~s}^{2}+19 \mathrm{~s}+0.93\right)}{\mathrm{s}\left(\mathrm{s}^{2}+30.041 \mathrm{~s}+45.04\right)}
$$

Due to similarity of two areas, the compensator of area II can designed like area I. Plant Templates

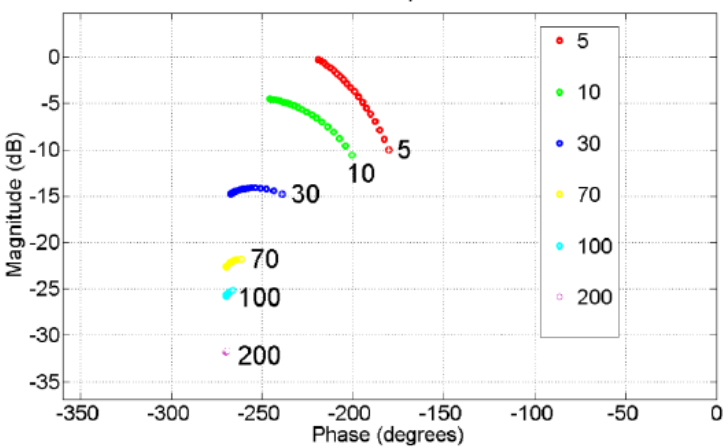

Fig.6. Plant templates 
UGC Approved Journal

IJIREEICE

\section{International Journal of Innovative Research in Electrical, Electronics, Instrumentation and Control Engineering \\ ISO 3297:2007 Certified}

Vol. 5, Issue 6, June 2017

\section{SIMULATION RESULTS}

To show the performance of the recommended controller for different scenarios of bilateral contracts under various operating conditions as well as vast demands of load and its effectiveness and robustness against parametric uncertainties and un-contracted loads, simulation is performed for the deregulated two area power system with the typical values of parameters as mentioned in table I and II (Appendix).

A. Scenario I: Bilateral Contracts

In this case the entire DISCOs contract with the GENCOs in their own or other areas base on following DPM

$$
D P M=\left(\begin{array}{cccc}
0.1 & 1 & 0.25 & 0.4 \\
0.7 & 0 & 0.25 & 0 \\
0 & 0 & 0.25 & 0.1 \\
0.2 & 0 & 0.25 & 0.5
\end{array}\right)
$$

It is assumed that the demand of any DISCO is $0.1 \mathrm{pu} \mathrm{MW}$ and the GENCO participation factors are defines as $\operatorname{apf}_{1}=0.75, \quad \operatorname{apf}_{2}=1-\operatorname{apf}_{1}=0.25$

$\operatorname{apf}_{3}=0.5, \quad \quad \operatorname{apf}_{4}=1-\operatorname{apf}_{3}=0.5$

Using this data, the simulation results are depicted in Fig.6. The figure shows, the frequency deviation of each area and the tie-line power go to zero in steady state. Also it can be seen that the dynamical response of the QFT controller is aggressive than two other solutions. As DISCOs in one area have contracts with GENCOs in another area, the off diagonal blocks of the DPM is not zero and actual tie line power settles scheduled power on the tie line in the steady state according to(1),(Fig.7(c)).

\section{B. Scenario II: Contract Violation}

It is assumed that some DISCOs violate a contract by demanding more or less power than specified in the contract. This uncontracted power must be supplied by the same area's GENCOs. For this case, consider DPM as in scenario I with $0.1 \mathrm{pu}$ MW excess power demanded by DISCO2.

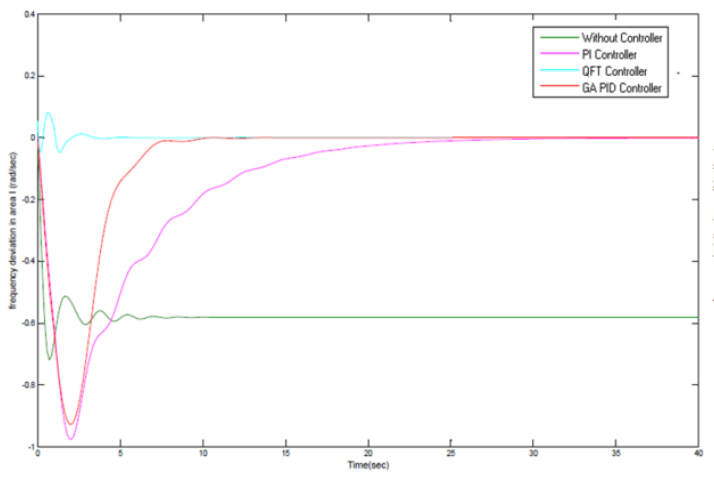

(a)

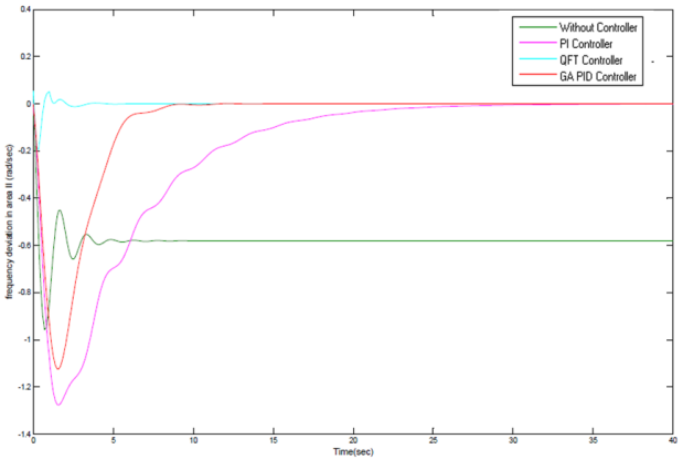

(b)

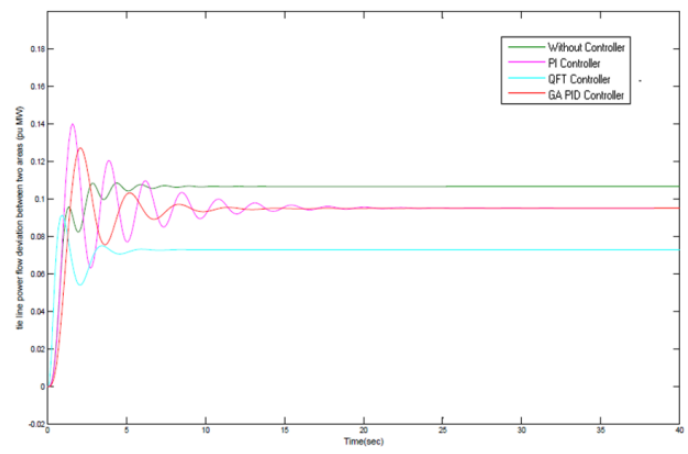

(c) $\mathrm{S}$

Fig.7. Scenario 1: (a) Frequency deviation in area I (rad/s), (b) Frequency deviation in area II (rad/s), (c) Tie-line power flow deviation (pu MW)

Total load in area I $=$ demand of DISCO1+ demand of DISCO2 $=(0.1)+(0.1+0.1)=0.3 \mathrm{pu} \mathrm{MW}$

Total load in area II $=$ demand of DISCO3 + demand of DISCO $4=0.2 \mathrm{pu} \mathrm{MW}$ 


\section{UGC Approved Journal}

IJIREEICE

\section{International Journal of Innovative Research in Electrical, Electronics, Instrumentation and Control Engineering \\ ISO 3297:2007 Certified}

Vol. 5, Issue 6, June 2017

Fig.7 illustrates the frequency deviation and tie lie power flow between areas. The simulation results show that the proposed robust controller tracks the excess power demand better than the conventional type controller. It should be mentioned that because DPM is the same as in case I and the uncontracted load is taken up by GENCOs in the same area, the tie line power flow is similar to first scenario in steady state (Fig.8(c)).

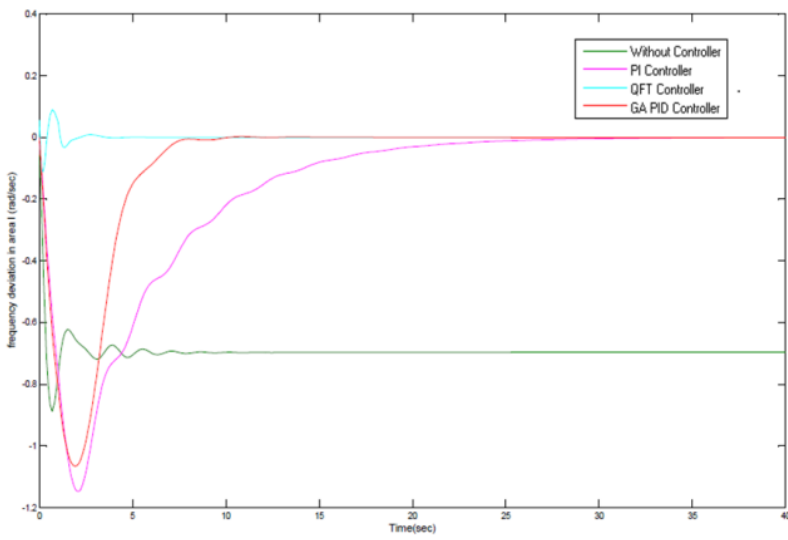

(a)

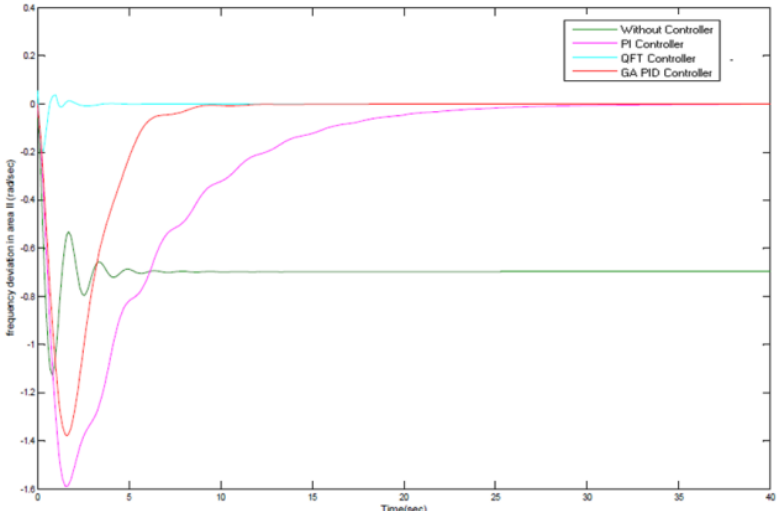

(b)

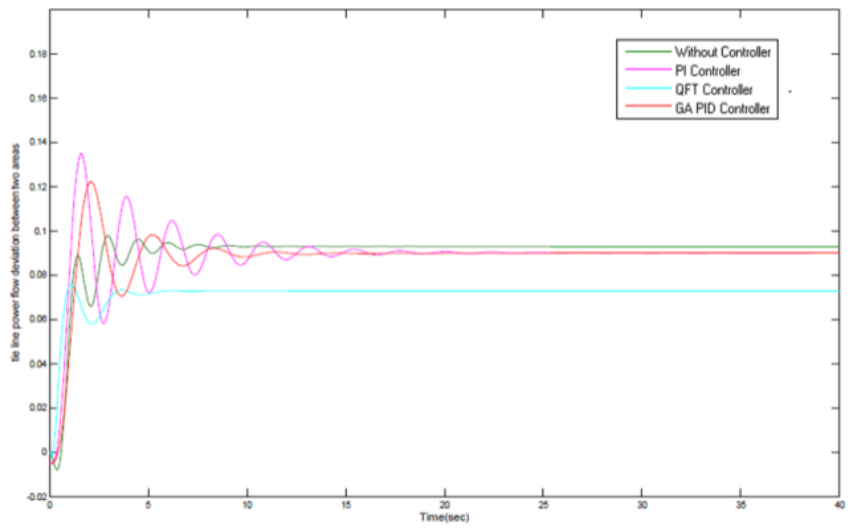

(c)

Fig.8. Scenario 2: (a)Frequency deviation in area I (rad/s), (b) Frequency deviation in area II (rad/s), (c) Tie-line power flow deviation (pu MW).

C. Parametric changes of power system

In this case, to show the robustness of proposed QFT controller, power system parameters have been changed $35 \%$ from their nominal values. Considering DPM of scenario I, simulation has been performed on the uncertain power system and the results are shown in Fig. 9. From this figure, the power system with Integral type controller or without controller does not satisfy the LFC requirements while the QFT controller leads the frequency deviation and tie line power flow to desired values in the steady state.

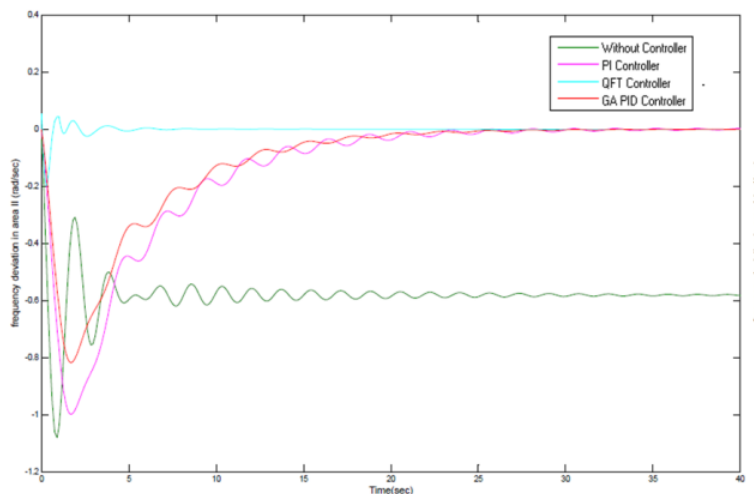

(a)

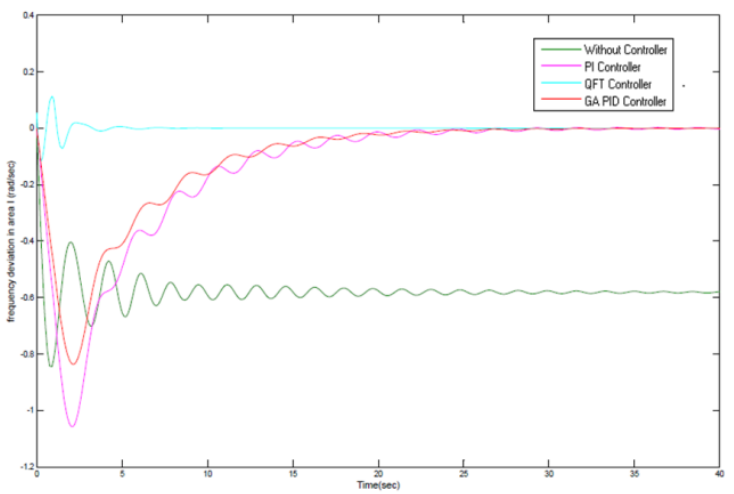

(b) 
UGC Approved Journal

IJIREEICE

\section{International Journal of Innovative Research in Electrical, Electronics, Instrumentation and Control Engineering \\ ISO 3297:2007 Certified}

Vol. 5, Issue 6, June 2017

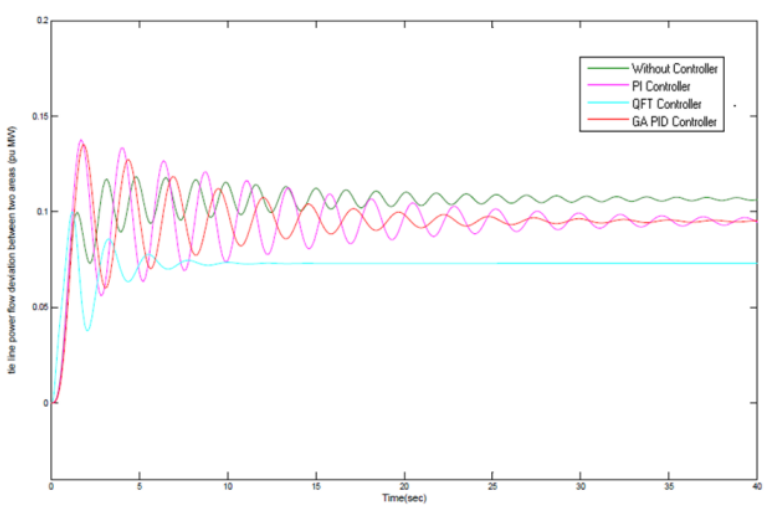

(c)

Fig.9. Parameter change: (a) Frequency deviation in area I (rad/s), (b)Frequency deviation in area II(rad/s), (c) Tie-line power flow deviation(pu MW).

\section{CONCLUSION}

To load frequency control problem of the multi area power system after deregulation considering bilateral contracts has been investigated in this paper. Because of various disturbances and uncertainties of complex restructured power system, conventional controllers give non-proper dynamical responses especially for the load frequency control problem. In this study a new improved method using quantitative feedback theory has been used to design a decentralized robust controller for power system. In order to show the effectiveness of the proposed controller, simulation has been done on a two area power system in which the effects of restructuring in competitive environment has been considered on the dynamics and the modified LFC scheme is obtained. A comparison has been done between the results of the QFT controller, the system without controller, the Integral type controller and real coded GA based PID controller for the cases of freely bilateral contracts between areas and contract violation by some DISCOs. The simulation results substantiate the high performance of suggested controller comparing conventional ones. The robustness of QFT method against power system nonlinearity and parametric uncertainties has been confirmed by simulation of the power system which its parameters values have been changed widely from their nominal values

\section{APPENDIX}

The parameters of power system for nominal operation is as follow

TABLE I GENCOs Parameters

\begin{tabular}{|c|c|c|c|c|}
\hline \multirow{2}{*}{ GENCOS } & \multicolumn{2}{|c|}{ Area I } & \multicolumn{2}{c|}{ Area II } \\
\cline { 2 - 5 } & GENCO1 & GENCO2 & GENCO3 & GENCO4 \\
\hline $\mathrm{T}_{\mathrm{t}}(\mathrm{s})$ & 0.3 & 0.3 & 0.32 & 0.3 \\
\hline $\mathrm{T}_{\mathrm{g}}(\mathrm{s})$ & 0.08 & 0.082 & 0.08 & 0.086 \\
\hline $\mathrm{R}$ & 2.4 & 2.4 & 2.5 & 2.6 \\
\hline
\end{tabular}

TABLE II Control Area Parameters

\begin{tabular}{|c|c|c|}
\hline Control area parameters & Area I & Area II \\
\hline $\mathrm{K}_{\mathrm{p}}$ & 120 & 120 \\
\hline $\mathrm{T}_{\mathrm{p}}$ & 20 & 20 \\
\hline $\mathrm{B}$ & 0.425 & 0.425 \\
\hline $\mathrm{T}_{12}$ & \multicolumn{2}{|c|}{0.545} \\
\hline
\end{tabular}

\section{REFERENCES}

[1] Javad Rezvantalab, M.H. Kazemi, A. Khaki Seddigh, "Multi-area Robust Decentralized Load Frequency Controller Design in a Restructured Power System Using Quantitative Feedback Theory,” IEEE Trans. On Power Systems, 2009.

[2] Javad Sadeh and Elyas Rakshani, “ Multi area load frequency control on deregulated power system using optimal output feedback method," IEEE Transaction, 978-1-4244-1744-5/08. 


\section{International Journal of Innovative Research in Electrical, Electronics, Instrumentation and Control Engineering \\ ISO 3297:2007 Certified}

Vol. 5, Issue 6, June 2017

[3] O.I. Elgerd and C. Fosha, "Optimum megawatt-frequency control of multi area electric energy systems," IEEE Trans. Power Apparatus \& Systems, vol. PAS-89, no. 4, pp. 556-563, Apr. 1970.

[4] C. Fosha and O.I. Elgerd, "The megawatt-frequency control problem: A new approach via optimal control theory," IEEE Trans. Power Apparatus \& Systems, vol. PAS-89, no4, pp. 563-577, Apr. 1970

[5] V. Donde, A. Pai , and I.A. Hiskens, "Simulation and Optimization in a LFC System after Deregulation," IEEE Trans. On Power Systems, vol. 16, no.3, pp. 481-489, Aug. 2001

[6] D.E. Goldberg, "Genetic algorithms in search, Optimization and machine learning, reading", MA: Addision - wesely publishing Company, Inc., 1989.

[7] P.J. Fleming and C.M. Fronseca, "Genetic algorithms in control systems engineering", Research report No. 470, Dept. of Automatic control and systems engineering, university of Sheffield, Sheffield, U.K., 1993.

[8] A.P. Sakis Meliopoulos, G.J. Cokkinides, and A.G. Bakirtzis, "Load frequency control service in a deregulated environment," Energy Conversion and Management, vol. 24, pp. 243-250, 1999.

[9] R. Christie and A. Bose, "Load-frequency control issue is power system operation after deregulation," IEEE Trans. Power Systems, vol. 11, pp. 1191-1200, Aug. 1996.

[10] E. Nobile,A.Bose and K.Tomsovic, "Bilateral market for load following ancillary services," in Proc. PES Sumer Power Meeting, Seatle, WA, July $15-21,2000$.

[11] D. Rekpreedapong and A. Feliachi, "Decentralized Load Frequency Control for Load Following Services," IEEE Power Engineering Society Winter Meeting,vol. 2, no. 1, pp. 1252-1257, Jan. 2002.

[12] F. Liu, Y.H. Song, J. Ma, S. Mei and Q. Lu, "Optimal load-frequency control in restructured power system," IEEE Proceeeding Generation, Transmission and Distribution, vol. 150, no. 1, pp. 87-95, Jan. 2003.

[13] H. Bevrani, Y, "Robust Load Frequency Controller in a Deregulated Environment: A $\mu$ - synthesis Approach,” Proc. of IEEE Int. Conf. on Control Applications, pp. 616-621, USA, 1999.

[14] A. Feliachi, "Load frequency control using reduced order models and local observers," Electrical Power and Energy Systems, vol.7, no.2, pp. $72-75,1987$.

[15] I. Horowitz, "Survey of quantitative feedback theory," Int. J. Robust Nonlinear Control, 2001, Vol. 11, pp. 887-921.

[16] P.Shrikant Roa and I.Sen,"Robust tuning of power system using QFT," IEEE Trans. Control Systems Thechnology, vol. 7, no. 4, pp. 478- 486, July. 1999.

[17] C. Borghesani, Y. Chait, O. Yaniv, "The QFT frequency domain control design toolbox for use with Matlab, user 's guide," 2003.

[18] Constantine H Houpis, Constantine S. Houpis, Steven J. Ramussen, Quantitative Feedback Theory: fundamentals and applications, 2rd ed., Marcel Dekker, 1999.

[19] D'Azzo, J.J., and Houpis, C.H, Linear Control System Analysis and Design, McGraw-Hill, 1988.

\section{BIOGRAPHIES}

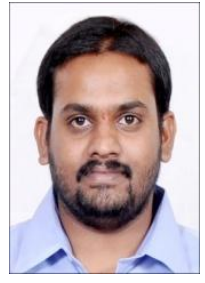

P. Bharat Kumar received B. Tech degree in Instrumentation and Control Engineering from the JNTU Hyderabad in 2007 and M. Tech degree in Control Systems from JNTUA Anantapur. He is currently working toward the $\mathrm{Ph}$. D. degree in Electrical Engineering at the JNTUA Ananthapuramu. His research interests include Controllers design using AI techniques, nonlinear control and Robust Control.

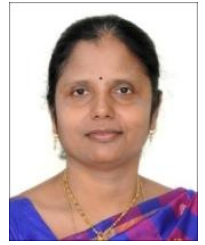

Dr. P. Sujatha, presently working as a Professor in Department of Electrical and Electronics Engineering, J.N.T.U. A. College of Engineering, Ananthapuramu, Andhra Pradesh, India. She completed her B. Tech degree in 1993 and M. Tech Degree with specialization in Electrical Power Systems in 2003 \& Ph. D in 2012 from J.N.T.U.A, Anantapur, Andhra Pradesh, India. She has nearly 17 years of teaching experience and her areas of interest include Reliability Engineering with emphasis to Power Systems and Real time Energy Management. 